\title{
SSSC to control Power flow in the Line
}

\author{
D.O.I - $10.51201 /$ Jusst 12530 \\ http://doi.org/10.51201/Jusst12530
}

\author{
Sandeep R. Gaigowal ${ }^{1 *},{ }^{2}$ Rohan S. Khonde, ${ }^{3}$ Dhiraj N. Katole \\ ${ }^{1,2}$ Department of Electrical Engineering, Yeshwantrao Chavan College of Engineering, \\ Nagpur, (M.S.) India \\ ${ }^{3}$ Department of Electrical Engineering, J. L. Chaturvedi College of Engineering, Nagpur,
}

(M.S.) India

\begin{abstract}
FACTS controller is the Power Electronics based static controller which enhance power transfer capability and increase controllability of the power system network. Static Synchronous Series Compensator (SSSC) is VSC based controller which is used in transmission network with the aim of utilization of existing line upto its fullest extent. This paper demonstrates transmission line power flow control with the help of SSSC. A control scheme of SSSC is presented to control active power flow in the line. Increase in the power flow in the line is realized with SSSC operation in capacitive mode of operation and decrease in the power flow is realized with SSSC operated in inductive mode of operation. MATLAB simulation studies are demonstrated to validate the SSSC operation.
\end{abstract}

Keywords: Flexible AC Transmission System (FACTS), Active power flow control, Static Synchronous Series Compensator (SSSC)

\section{Introduction}

Electric power generation is increasing day by day to fulfil the increasing load demand. Along with thermal power plants, power generation by renewable energy is inserting much more electrical power in the existing grid. Transmission network has not been so increased in proportion as the generation is increased. As a result, transmission network is operating overloaded; at the same time some of the lines may be operating underloaded. This uncontrolled power flow may give congestion in the existing network. Numerous problems in expansion of transmission lines are forcing existing transmission network to utilise upto its fullest extent. FACTS controllers are capable of controlling power flow in the line upto its thermal limits. FACTS controllers are able to transmission parameters like voltage $\mathrm{V}$, line impedance and power angle. FACTS controllers are providing wide control over active and reactive power flow and increases reliability of AC grids [1]. Conventional FACTS controllers like TCSC, GCSC, SVC incorporating inductor $\mathrm{L}$ and capacitor $\mathrm{C}$ circuit is controlled by power electronics devices. Advantageous fast acting and high power electronics switches are applied in voltage sources converter (VSC) based FACTS controllers, e.g. STATCOM, SSSC and UPFC [2]-[4]. STATCOM is VSC based shunt connected FACTS controller to regulate the bus voltage by exchanging reactive power in the system. With the help of STATCOM reactive power is injected in the system or absorb from the system to maintain bus voltage in specified limits. STATCOM comprises of high power rating VSC connected in shunt at PCC. It has numerous advantages, major in reactive power control to regulate the bus voltage. Static synchronous series compensator (SSSC) is VSC based FACTS controllers connected in series with the line mainly to control active power flow in the line. Reactance compensation can be realized by SSSC to control active power flow in the line [5]-[6]. SSSC consists of VSC which is connected in series with the transmission line 
through coupling transformer. A combination of STATCOM and SSSC, a new versatile FACTS controller named UPFC is a shunt series FACTS controller. It consists of shunt and series FACTS controller i.e. STATCOM and SSSC. A common dc link is provided to pass on active power needed in series FACTS controller i.e. SSSC. UPFC has wide control capability. It injects voltage in the line at any angle from $0^{\circ}$ to $360^{\circ}$. Deepak Divan introduced Distributed FACTS concept to realize power flow control in cost effective and more reliable way [7]-[8].

In this paper, SSSC operation is demonstrated to regulate active power flow in the line as per requirement. A control scheme is implemented to control active power flow as desired. Presiding to introduction, SSSC construction and operation is presented next section. SSSC control scheme is demonstrated. In the last section, SSSC MATLAB simulation studies are presented.

\section{Static Synchronous Series Compensator (SSSC)}

Consider a two bus system shown in Fig. 1 below. Active and reactive power flow in the transmission line can be controlled by bus voltage $V$ and line reactance $X_{L}$. Power angle $\delta$. Can also be altered to control power in the line/

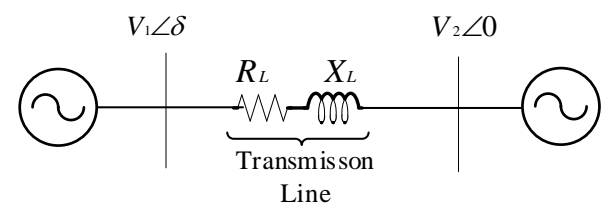

Fig. 1. Two generator system

Neglecting line resistance, the expression of active and reactive power is shown below in equation (1) and (2),

$$
\begin{gathered}
p=\frac{V_{1} V_{2}}{X_{L}} \sin \delta \\
Q=\frac{V_{1}^{2}-V_{1} V_{2} \cos \delta}{X_{L}}
\end{gathered}
$$
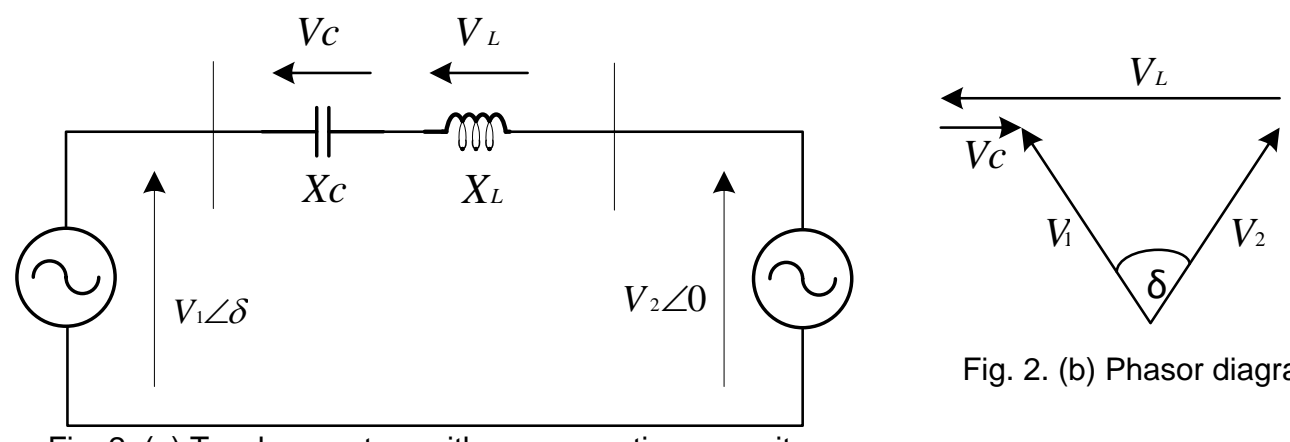

Fig. 2. (b) Phasor diagram

Fig. 2. (a) Two bus system with compensating capacitor

Fig.2 shows two bus system with series capacitive compensation, a capacitor is inserted in series with the line. It reduces effective reactance; active power is increased. Active power flow increase with the help of capacitor in series with the transmission line. The same active power flow control can be obtained by connecting SSSC in series with the line. Static synchronous series compensator 
(SSSC) is a series connected FACTS device. Fig. 3 shows SSSC connected with the line in series. Voltage source converter (VSC) is connected in series the line through coupling transformer. Secondary of VSC is connected to DC link capacitor [9].

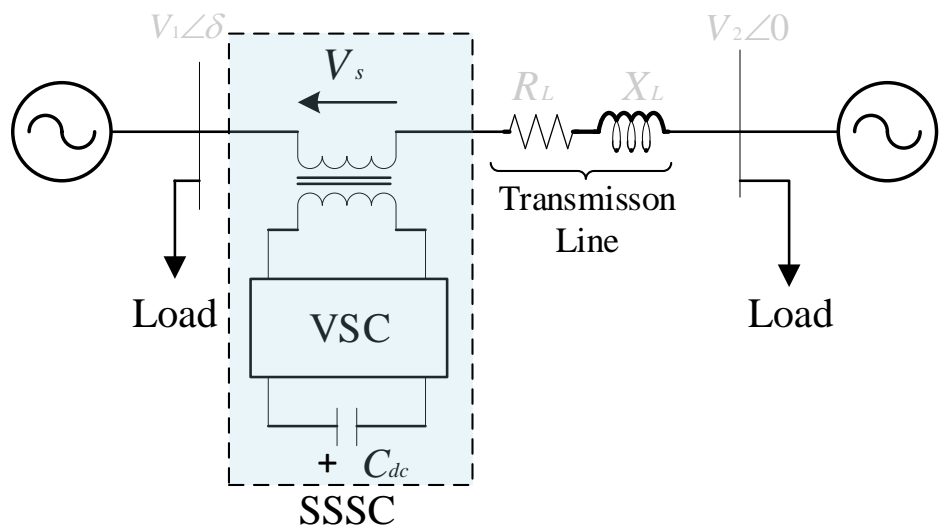

Fig.3. SSSC connected in series with Line

SSSC is a series connected FACTS controller to realize reactance compensation in the line. A high power rating VSC is used with the help of coupling transformer for series connection with the line. SSSC injects voltage in series with the line at $90^{\circ}$ lagging or leading to line current. If injected voltage lags line current, it realizes capacitive reactance in the line. Effective line reactance will be reduced, which results in increase in active power flow in the line. Similarly, if injected voltage leads line current at $90^{\circ}$, it realizes inductive reactance in the line which increases effective line reactance. As a result, active power flow in the line decreases. With SSSC compensation, Active and reactive power expression is given by,

$$
P c=\frac{V^{2}}{X} \sin \delta+\frac{V}{X} \cos \frac{\delta}{2}
$$

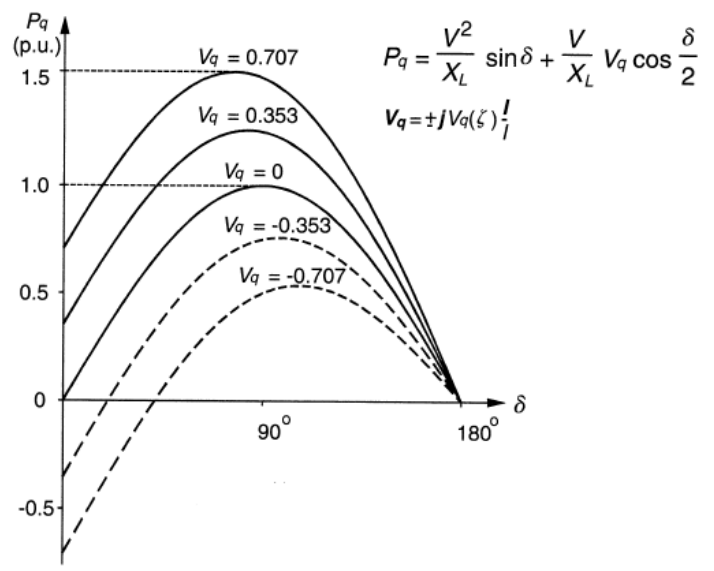

Fig.4.P- $\delta$ Curve SSSC incorporated system

Transmitted power vs. transmission angle provided by SSSC as the series compensating voltage shown in Fig.4.

\section{SSSC Control Scheme}

Fig. 6 shows control scheme explained by Kalyan Sen [10]. A DC link capacitor voltage is maintained to control active power as per requirement. Line current and DC link voltage are the measurable quantities. Voltage V1 is measured to find PLL angle. In this control scheme, reference reactance Xq to be injected is calculated with respect to desired active power increase or decrease in the line. 


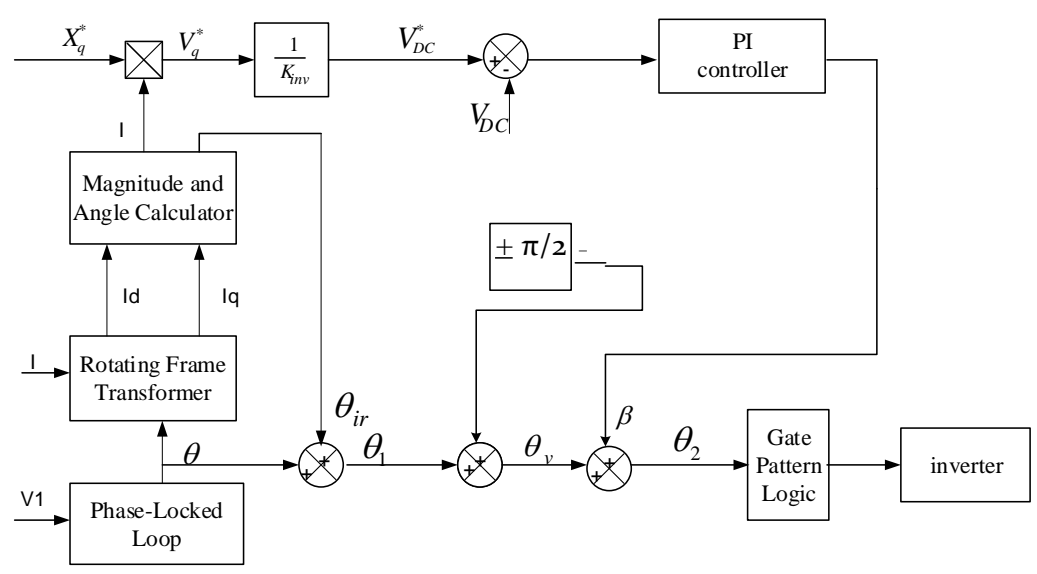

Fig.5. Control scheme [9]

In this control scheme, DC link voltage is maintained with reference to desired active power flow in the line. Angle $\Theta$ is the reference angle calculated with the help of phase locked loop (PLL). It gives phase synchronism with bus voltage V. Three phase line current I is converted to two phase d-q components Id and Iq. Magnitude and angle with respect to reference angle $\Theta$ is calculated. Reference injected voltage $\mathrm{Vq}^{*}$ is calculated as $\mathrm{Vq}^{*}=\mathrm{Xq}^{*} \mathrm{I}$ where $\mathrm{Xq}^{*}$ is the reference reactance injected. Compensating reactance demand $\mathrm{Xq}^{*}$ is multiplied by current magnitude, $\mathrm{Vq}=\left(\mathrm{Xq}^{*}\right)(\mathrm{I})$. DC link voltage is obtained by using inverter gain. This DC link voltage is compared with actual voltage across DC link. The error is passed through PI controller. It gives correction angle $\beta$. According to selection of operation mode, $+90^{\circ}$ or $-90^{\circ}$ is selected. Pulses are generated with respect to the angle calculated $\Theta+90^{\circ}+\beta$. Generated pulses are given to VSC which gives injected voltage at 900 lagging or leading to line current.

\section{System Studies}

System studies are carried out on the system shown in Fig. 6 below. Base MVA is taken 100 MVA and base voltage is $230 \mathrm{kV}$. When compensation is not applied, active power transmitted in the line is found $120 \mathrm{MW}$ and $320 \mathrm{MVAr}$ when load 1 is connected only.

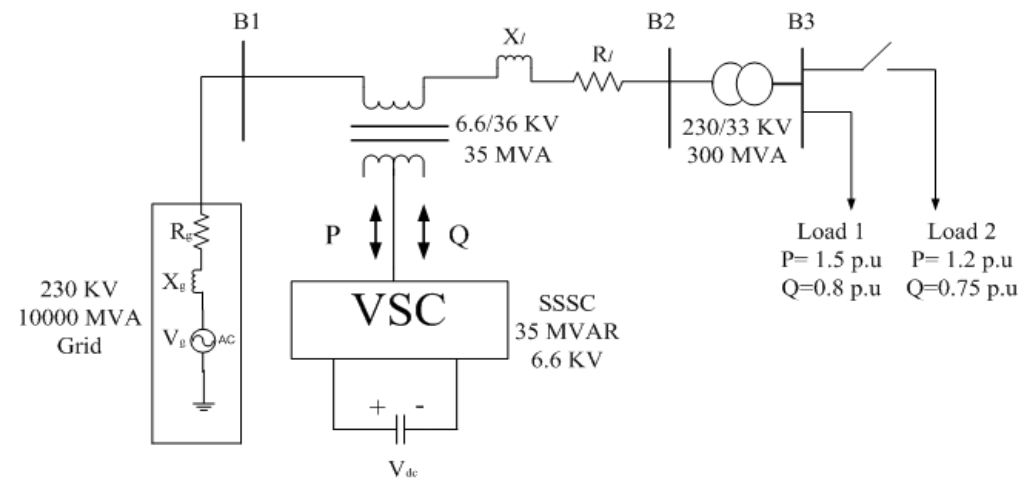

Fig. 6 System for SSSC simulation [11]-[12]

A control scheme is implemented in SSSC operation. SSSC operation in inductive mode of operation is given in Fig.7. SSSC is operated at $t=0.4 \mathrm{sec}$. Voltage is injected voltage leading to line current. The phase displacement between voltage injected and line current is $90^{\circ}$. DC link voltage is maintained at $11.5 \mathrm{kV}$ to get $38 \mathrm{kV}$ voltage injected in the line. Current in the line is reduced from $0.6 \mathrm{kA}$ to $0.5 \mathrm{kA}$. Active power is decreased to $120 \mathrm{MW}$ to $100 \mathrm{MW}$.

Capacitive mode of operation is shown in Fig. 8. SSSC is operated in capacitive mode of operation at $\mathrm{t}=0.4 \mathrm{sec}$. Injected voltage is lagging to line current at $90^{\circ}$. To get $50 \mathrm{kV}$ voltage injected in 
leading mode of operation, dc link voltage is maintained at $20 \mathrm{kV}$. The active power is increased to 205 MW.

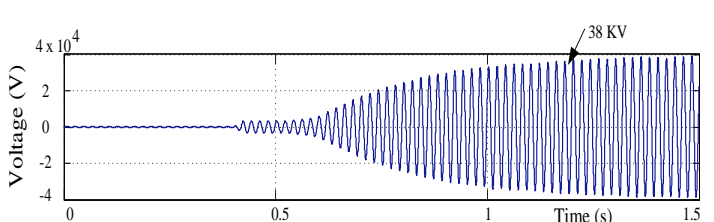

(a)

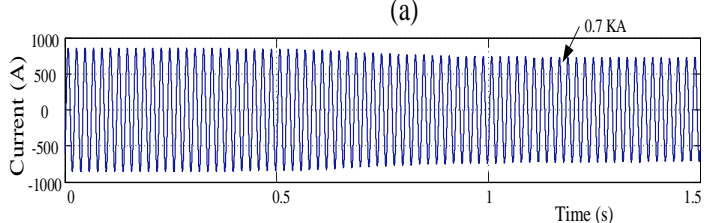

(b)

Fig. 7(a) Injected voltage (b) Line current in inductive mode of operation at $t=0.4 \mathrm{sec}$

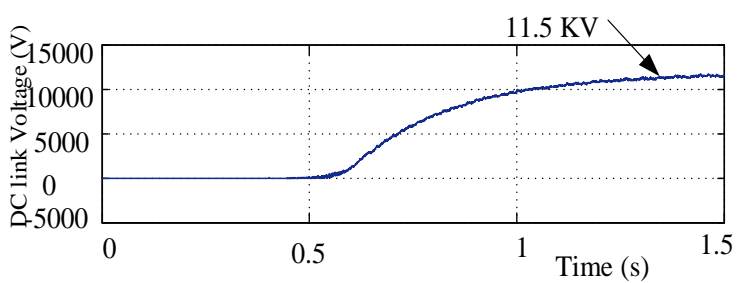

Fig. 7(c) DC link voltage in inductive mode of operation
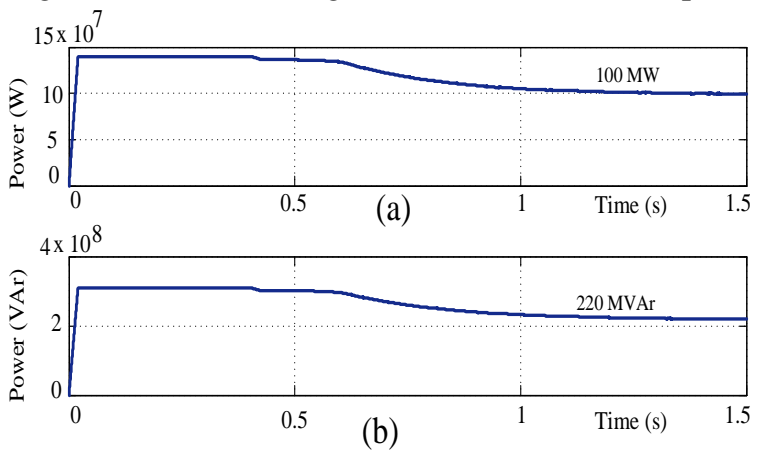

Fig. 7(d)Active and reactive power in inductive mode of operation
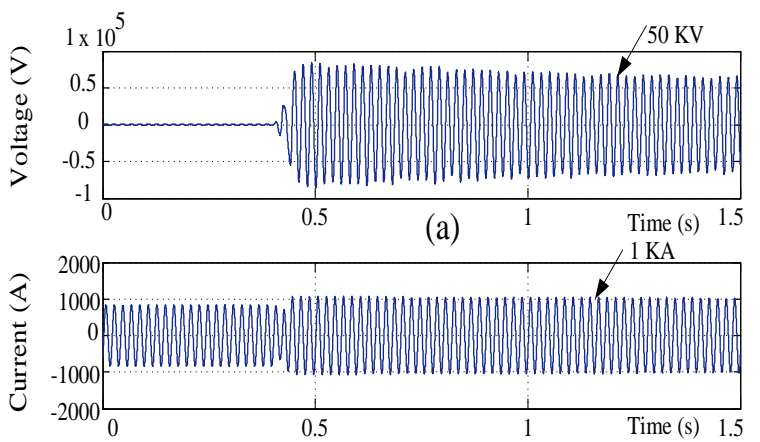

(b)

Fig. 8(a) Injected voltage 8(b) Line current in capacitive mode of operation at $t=0.4 \mathrm{sec}$

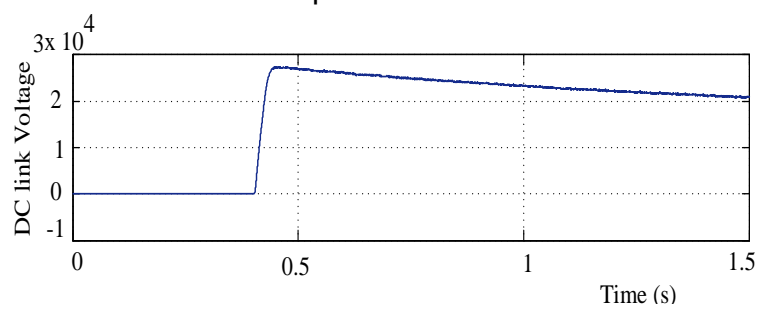

Fig. 8(c) DC link voltage in capacitive mode of operation
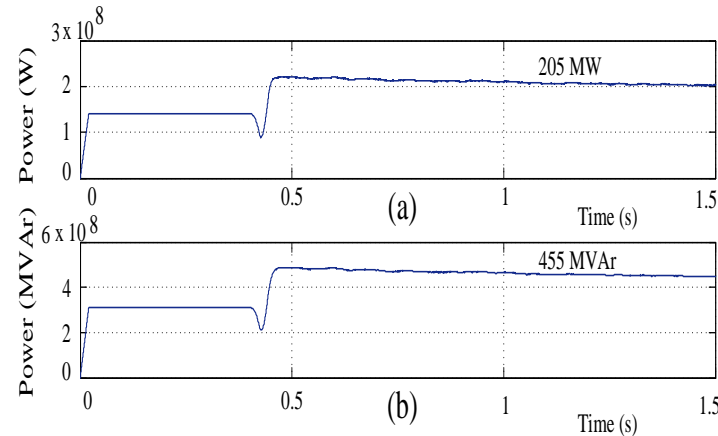

Fig. 8(d) Active and reactive power in capacitive mode of operation

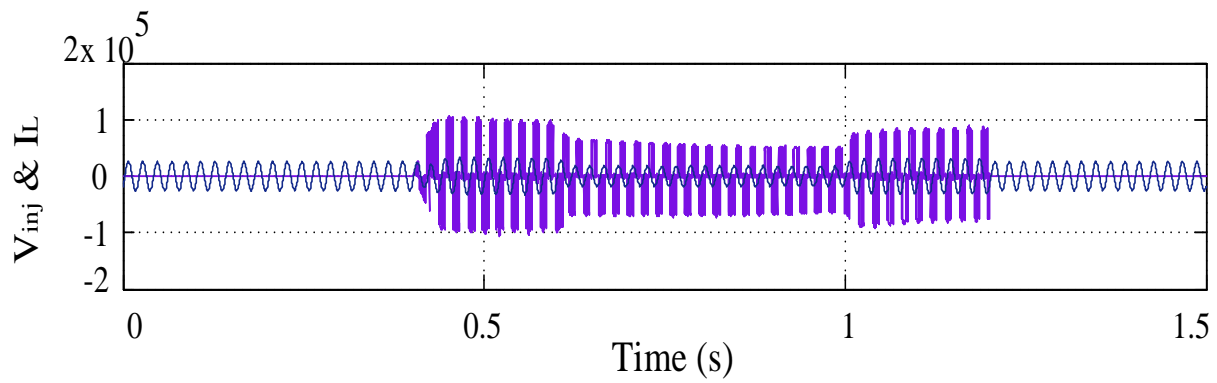

Fig. 9 Injected voltage and line current

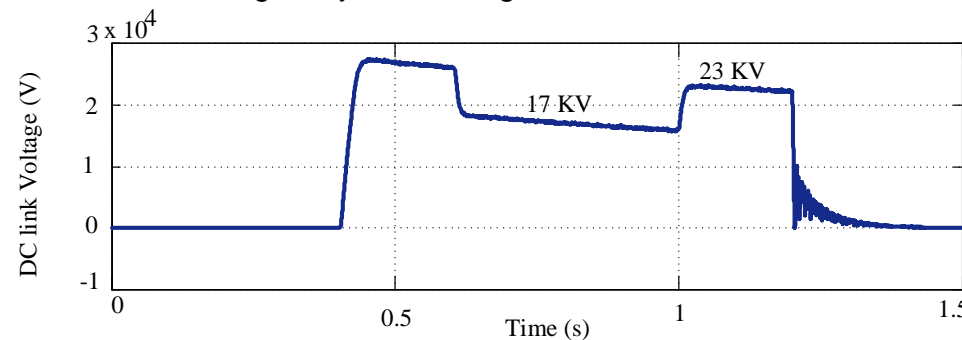

Fig. 10 DC link voltage 


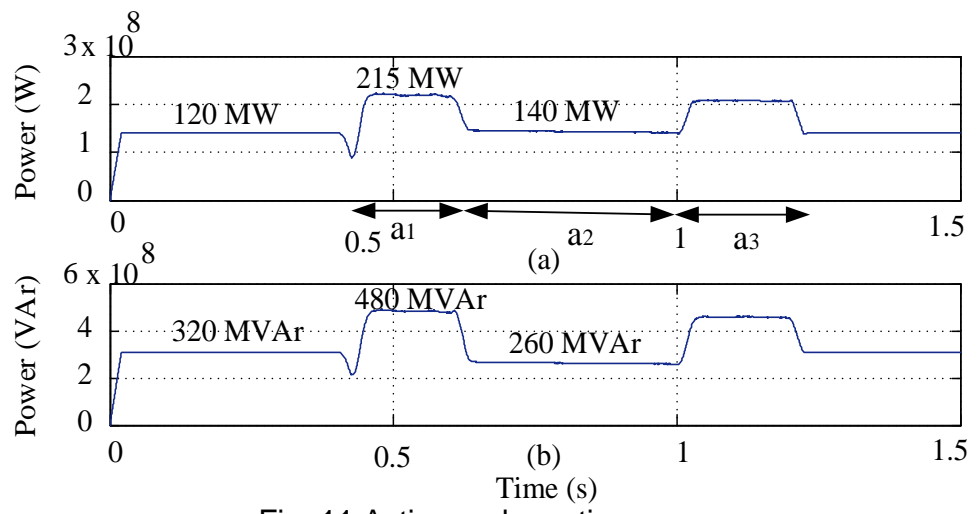

Fig. 11 Active and reactive power

A dynamic performance is also demonstrated as shown in Fig. 10 and Fig. 11. The results are carried out by connecting the SSSC in series with both loads. From $t=0.4 \sec$ to $t=1.2 \mathrm{sec}$ the $\mathrm{SSSC}$ is connected. From $\mathrm{t}=0.4 \mathrm{sec}$ to $\mathrm{t}=0.7 \mathrm{sec}$, load 1 and 2 both are connected, power is increased. From $t=0.7 \mathrm{sec}$ to $t=1.0 \mathrm{sec}$ load 2 is removed, the power is decreased and thereafter again load 1 and 2 both are connected. A DC link voltage is regulated as per the load change.

\section{Conclusion}

Static synchronous series compensator is FACTS compensator which controls active power flow in transmission line. MATLAB simulation results are presented in the paper. SSSC operated in capacitive mode of operation gives increase in power flow in the line and SSSC operated in inductive mode of operation decreases active power flow in the line. A dynamic performance is demonstrated with different load connected. As per requirement, DC link voltage is maintained to control power flow.

\section{REFERENCES}

[1] N. G. Hingorani, L. Gyugyi, "Understanding FACTS: Concepts and Technology of Flexible AC Transmission Systems," IEEE Press, (2000).

[2] Kalyan K. Sen and Eric J. Stacey, "UPFC-Unified Power Flow Controller: Theory, Modelling and Applications", IEE Transactions on Power Delivery, Vol. 13, No. 4, (1998).

[3] R. M. Mathur and R. K. Varma, Thyristor-based FACTS Controllers for Electrical Transmission Systems, IEEE Power Engineering Society, IEEE Press, Piscataway, NJ, (2002).

[4] Acha, E., C.R. Fuerte-Esquivel, H. Ambriz-Pe'rez, and C. Angeles-Camacho. (2004). "FACTS: Modelling and Simulation in Power Networks, "John Wiley and Sons

[5] L, Sunil Kumar and Arindam Ghosh, "Modeling and Control Design of a Static Synchronous Series Compensator", IEEE Trans. on Power Delivery, Vol. 14, No. 4, (1999)

[6] M. Ebeed, S. Kamel and F. Jurado, "Constraints violation handling of SSSC with multi-control modes in newton-raphson load flow algorithm", IEEJ Trans. Electr. Electron. Eng., vol. 12, no. 6, pp. 861-866, (2017)

[7] Deepak. M. Divan, W. E. Brumsickle, R. S. Schneider, B. Kranz, R. W. Gascoigne, D. T. Bradshaw, M. R. Ingram, and I. S. Grant, " A distributed static series compensator system for realizing active power flow control on existing power lines", IEEE Trans. on Power system, vol. 22, no.1, pp. 642-649, (2007).

[8] Sandeep R. Gaigowal and Dr. M. M. Renge, "Some studies of Distributed Series FACTS Controller to control active power flow through Transmission Line", IEEE International Conference on Power, Energy and Control (ICPEC), pp 124-128, (2013)

[9] L. Gyugyi, C. D. Schauder, and K. K. Sen, "Static Series Compensator: a Solid-State Approach to the Series Compensation of Transmission Lines," IEEE Transactions on Power Delivery, Vol. 12, No. 1,(1997), pp. 406-407.

[10] Kalyan K. Sen, "SSSC: Theory, modeling and applications", IEEE Transactions on Power Delivery, vol. 13, No. 1, (1998).

[11]. El-Moursi and A. M. Sharaf, "Novel Controllers for the 48-Pulse VSC STATCOM and SSSC for Voltage Regulation and Reactive Power Compensation", IEEE Transactions on Power Systems, Vol. 20, No. 4, (2005).

[12]. Amir H. Norouzi and A. M. Sharaf, "Two Control Schemes to Enhance the Dynamic Performance of the STATCOM and SSSC", IEEE Transactions on Power Delivery, Vol. 20, No. 1, (2005). 